\title{
Turismo Urbano em São Paulo: reflexões teóricas e apontamentos empíricos
}

\author{
Urban Tourism in São Paulo: theoretical considerations and empirical evidences
}

Turismo Urbano en São Paulo: reflexiones teóricas y apuntes empíricos

Thiago Allis ${ }^{1}$

Heliana Comin Vargas ${ }^{2}$

\begin{abstract}
Resumo
Este trabalho discute o turismo urbano em São Paulo, tendo por argumento que, em grandes cidades, é imprescindível conhecer os perfis de seus visitantes, entendidos como "consumidores de lugar" (SELBY, 2004b). Para além dos dados oficiais disponibilizados pelo órgão local de turismo (São Paulo Turismo S/A), a unidade de análise empírica foram os 52 atrativos turísticos da cidade, elencados e selecionados a partir da consulta aos principais guias turísticos e fontes de informação turística sobre a cidade de São Paulo. Foram concebidos e distribuídos formulários eletrônicos a gestores desses atrativos, na perspectiva de identificar as origens dos visitantes, já que estas informações, até o presente, não estão consolidadas em uma base dados única. Como resultados, depreende-se que os principais atrativos da cidade são efetivamente visitados por moradores da Região Metropolitana de São Paulo, sugerindo que a análise e a gestãodo turismo na cidade de São Paulo devem levar em conta aspectos também de públicos locais e metropolitanos e explicitando a urgência de se realizarem levantamentos sistemáticos, abrangentes e inovadores relativos aos perfis dos "usuários da cidade" (MARTINOTTI, s/d). Entender suas características (origens, padrões de deslocamento, demandas, perfil de gastos, avaliação das experiências etc) pode contribuir para o alinhamento entre políticas urbanas e outras inicitivas de planejamento e gestão do turismo em contextos urbanos.
\end{abstract}

Palavras-chave: Planejamento urbano; Atrativos turísticos, São Paulo (Brasil)

\footnotetext{
1 Professor da Universidade Federal de São Carlos, Campus Sorocaba. Doutor em Planejamento Urbano e Regional -FAU-USP. Brasil. E-mail: thiagoallis@usfcar.br

${ }^{2}$ Professora Titular da Faculdade de Arquitetura e Urbanismo da Universidade de São Paulo, departamento de projeto. Mestre e Doutora em arquitetura e urbanismo pela FAU-USP; Pós-doutorado, em Formação de Lideranças para o Planejamento Ambiental, em Genebra, na Academia Internacional de Meio Ambiente. Brasil. E-mail: hcvargas@usp.br
} 


\begin{abstract}
This essay discusses urban tourism in São Paulo, arguing that in large cities it's imperative to consider visitors' behavior, understanding them as "place consumers" (SELBY, 2004b). In addition to official data provided by the local official authority (São Paulo Turismo S/A), 52 tourist attractions have been considered as the basic research unit, selected from a detailed review over the most renowned tourist guides and tourist information sources for the city of São Paulo. Their managers were asked to answer an electronic formular, whose aim was to categorize the origins of the visitors, among other information, yet not available in a single data-base. As result, it's possible to state that the main tourist attractions in São Paulo are effectively visited by visitors from the São Paulo Metropolitan Area. It suggests that tourism planning and management in São Paulo have to take into account this audience and depicts urgency for broand and innovative regular data collection regarding the profiles of the "city users" (MARTINOTTI, s/d). To understand its characteristics (origins, displacement patterns, demands, spendings profile, experiences assessment etc) can contribute to coordinate urban policies with other tourism planning initiatives in urban contexts.
\end{abstract}

Keywords: Urban planning; Tourist attractions; São Paulo (SP).

\title{
Resumen
}

Este artículo discute el turismo urbano em São Paulo, teniendo por argumento la idea de que em grandes ciudades és imprescidible considerar el comportamiento de los visitantes, entendidos como "consumidores de lugares" (SELBY, 2004b). Además de una recolección de datos en las autoridades oficiales de turismo de São Paulo, 52 atracciones turísticas se consideraran como la unidad básica de la investigación, cuya selección se hizo trás un revisión en las guías turísticas más conocidas y otras fuentes de información turística para la ciudad de São Paulo. Se solicitó a los gestores que rellenasen formulários electrónicos, con el objetivo de identificar los orígenes de los visitantes, entre otras informaciones, que no están todavía recopiladas en una base de datos. Como resultado, és posible reconocer que las principales atracciones turísticas de São Paulo son visitadas efectivamente por moradores de la Región Metropolitana de São Paulo. Eso sugiere que la planificación y gestión del turismo en São Paulo deben considerar inclusive estes públicos y indica la urgencia de poner en marcha abordajes sistemáticas, amplias y innovadoras acerca de los perfiles de los "usuários de ciudades" (MARTINOTTI, s/d). Entender sus características (orígenes, patrones de deslocamientos, demandas, perfiles de gastos, evaluaciones de experiencias, etc) suele contribuir para que se coordinen politicas urbanas con outras iniciativas de planificación de turismo en contextos urbanos.

Palabras-clave: Planificación urbana; Atractivos turísticos; São Paulo (SP) 


\section{Introdução}

Nas últimas décadas, São Paulo vem experimentando uma mudança significativa no seu poder de atração (oportunidades de emprego e negócios, opções de lazer e cultura, disponibilidade e diversidade de serviços médicos e especializados etc) assumindo alguns atributos - positivos e negativos - que a qualificariam como "cidade global" (SASSEN, 1991).

A cidade, que floresceu efetivamente a partir da expansão do complexo cafeeiro (final do século XIX emeados do século XX), desenvolveu-se mais fortemente quando de sua industrialização (a partir das primeiras décadas do século $\mathrm{XX}$ ), conduzindo-a ao estado de maior cidade brasileira e uma das maiores do mundo. Esta expansão urbana ensejou grandes ondas migratórias, inicialmente de estrangeiros e, depois, brasileiros de outras regiões do país. Na década de 1950, São Paulo ultrapassaria, em termos populacionais, o Rio de Janeiro em decorrência de sua proeminência econômica.

Ate meados do século $\mathrm{XX}$, a transformação da paisagem urbana ocorreu em função das demandas das elites locais, desejosas por construir a imagem de uma urbe cosmopolita em contraste com seu passado provinciano, caracterizando-se por intervenções urbanas na linha do embelezamento (ALLIS, 2012). A dinamização econômica viria, por sua vez, a promover um descompasso entre o crescimento econômico e demográfico e a gestão urbana, incapaz de garantir as condições mínimas com relação à qualidade de vida. Tal desalinho irá se refletir no ambiente construído de várias maneiras: processo de urbanização periférica centrado nas ocupações pela população de baixa renda; abandono de áreas urbanas históricas e consolidadas; imagem da cidade, marcada pelas chaminés das indústrias fordistas poluidoras e com grandes plantas; a ausência de espaços públicos de qualidade com parte da sua história arquitetônica substituída (TOLEDO, 1983).

No entanto, a partir de 1970, este mesmo desenvolvimento econômico - que, apesar de excludente, criou uma forte demanda local - viabilizou o desenvolvimento de atividades de negócios, lazer e cultura para os mais variados segmentos, para além daqueles já existentes, como os serviços médicos e hospitalares, eventos acadêmicos e científicos.

Os registros sobre número de turistas em São Paulo é um tema que apenas recentemente vem sendo objeto de atenção específica. Dados da autoridade local de turismo (São Paulo Turismo S/A) apontam que, entre 2007 e 2010, houve um aumento de $14 \%$ no total de turistas, sendo a 
maior parte de turistas brasileiros. A taxa de ocupação média na rede hoteleira local apresenta uma tendência de aumento, passando de $67 \%$ a $68,4 \%$ no mesmo período. O monitoramento do ISS (Imposto Sobre Serviços) do grupo 13 - que considera os impostos e tributos pagos por empresas do setor de turismo, hotelaria, eventos e assemelhados - também é expressiva, atingindo mais de R\$ 150 milhões em 2010 (OBSERVATÓRIO DO TURISMO DE SÃO PAULO, 2011).

Atualmente, a principal motivação dos visitantes de São Paulo são os negócios e eventos (77\%), seguido de lazer $(9,6 \%)$ e 13,3\% em outros segmentos secundários - saúde, visita a parentes e amigos. Deve-se ressaltar que, destes, o turismo de negócios é o que tem maior participação de visitantes estrangeiros (quase 15\%). Como atividades complementares - ou seja, aquelas que se realizam quando da visita à cidade por conta da motivação principal ressaltam-se a gastronomia e as compras, praticadas por $56 \%$ dos turistas de São Paulo (PLATUM 2011-2014, 2011, p. 61-62).

Para se estudar o turismo em São Paulo, deve-se reconhecer que a apropriação dos lugares pela atividade turística nas grandes cidades não se realiza da mesma maneira que localidades onde o turismo é sua principal atividade econômica (a exemplo de áreas costeiras brasileiras). Nas primeiras, as atividades habituais misturam-se, conferindo vitalidade e a diversidade à cidade contemporânea, da qual o turista deseja usufruir. Este é um ponto de coincidência na visão dos estudiosos do turismo urbano (PEARCE, 2003; PAGE, 1995; LAW 2002; SELBY, 2008; SPIROU, 2011), especialmente quando tratam de entender as intervenções urbanas nas grandes cidades, que se convertem em espaços de consumo e fruição tanto para moradores, quanto para turistas.

Neste sentido, a concepção tradicional de "turista" não parece dar conta de explicar o avanço do turismo urbano na dinâmica de grandes cidades (como São Paulo), especialmente porque os comportamentos espaciais dos turistas e dos moradores são, em grande medida, semelhantes e se confundem.

As demandas locais e metropolitanas desempenham importante papel na manutenção de certas atividades e atrativos considerados essencialmente turísticos. Destarte, para entender o turismo urbano, seu rebatimento espacial e sua articulação com as funções urbanas é importante atentar para estes fluxos com origem local, bem como para as características e 
perfis destes visitantes. É preciso reconhecer que moradores dos aglomomerados urbanos são parcelas importantes para o estudo e a gestão do turismo na contemporaneidade.

\section{Turismo Urbano: conceitos, práticas e questões atuais}

Os principais investigadores do tema têm buscado entender o turismo urbano no contexto da urbanização contemporânea - particularmente em sua interface com as políticas e práticas de planejamento e gestão urbanos. Em geral, suas observações centram-se nos países desenvolvidos, principalmente EUA, Europa Ocidental e Austrália (Page, 1995; Judd, Fainstein, 1999; Pearce, 1999, 2001, 2003; Bull, Church, 2001; Costa, 2001; Law, 2001; Coles, 2003; Haylaret al, 2008; Selby, 2004a, 2004b; Spirou, 2011). Com mais ênfase, Mullins (1991) e Lucchiari (2004) propõem o conceito de "urbanização turística", que também leva a reflexões importantes na construção de um conceito de turismo urbano. No Brasil, Carvalho (2011), Shibaki (2010), Silva (2008), Teles (2006), Spolon (2006) e Braga (2005) abordam certos aspectos do turismo urbano em São Paulo - como planejamento, formação e promoção de ícones urbanos, dispersão da hotelaria pelo território -, além de abordagens mais gerais de Vargas $(1996,1998)$.

De maneira geral, o estudo do turismo urbano busca concatenar condicionantes e particularidades do turismo praticado nas cidades, principalmente nas grandes aglomerações, onde as motivações específicas das visitas não são claras (à diferença dos resorts litorâneos ou em cidades antigas com núcleo histórico característico). Isso porque a complexidade do processo de urbanização enseja, em si, inúmeras mediações entre as idiossincrasias paisagísticas da cidade e as motivações dos visitantes que costumam ser multivariadas, diferentemente de uma "urbanização turística" (MULLINS, 1991, 1999; PAIVA, 2011).

Com efeito, o turismo é apenas uma das funções da cidade, motivo pelo qual o conceito de urbanização turística não é suficiente para o entendimento amplo do turismo urbano, já que se está diante de um setor que se subsume na economia urbana. O mesmo argumento se aplica ao entedimento das intervenções urbanas e suas relações com o turismo, onde a intenção expressa no discurso que inclui o turismo como um dos seus objetivos - também se dilui (ALLIS, 2012). Portanto, os tipos de "cidade turística", conforme sugerido por Page (1995), nem sempre faz sentido, pois uma grande aglomeração urbana jamais terá a base de sua 
atividade no turismo, mesmo quando este setor aumentar sua participação. Portanto, a expressão espacial da atividade talvez não seja tão explítica ou amplamente distribuída pelo território.

Paralelamente, a dinâmica de uso do espaço também conduz à mesma dificuldade, pois existe uma mistura entre moradores e turistas (particularmente no que tange a seus "comportamentos espaciais"), incluindo sobreposição de demandas quando usufruem das estruturas e serviços em um mesmo contexto urbano (MAILTAND, 2010; PEARCE, 2003; SELBY, 2004a, 2004b). Por mais corriqueira que possa ser a paisagem urbana a seus moradores, os significados e as interações que se processam podem perfeitamente variar, de maneira que o residente, como sugerido por Walter Benjamin ${ }^{3}$, pode se converter, se assim o desejar, no flâneur, "perambulando" pela cidade, muitas vezes com o mesmo grau de estranhamento e deslumbramento de um turista, ainda que considerá-los viajantes ${ }^{4}$ possa parecer um exagero. De toda forma, pode ser útil buscar incorporar ao estudo do turismo urbano tanto os viajantes que chegam às cidades (turistas, neste caso), quanto os moradores que buscam experiências na sua própria cidade (ALLIS, 2014).

Haussermann e Colomb (2003, p. 210) relatam medidas de promoção de da cidade de Berlim tendo os moradores como público-alvo de ações de marketing urbano, como "uma ferramenta potencial para (re)criar o senso de identidade local, amenizar conflitos sobre novos empreendimentos na cidade ou estimular o potencial de desenvolvimento econômico endógeno". Igualmente, em Barcelona, "as festividades associadas com os jogos [olímpicos] de feiras públicas a eventos culturais - fortaleceram o patriotismo local e o orgulho cívico" (GARCÍA, CLAVER, 2003, p. 116-7). No limite, Maitland (2010, p. 178) sustenta que isso poderia estruturar um "turismo interno", quando "residentes consomem a cidade de maneiras similares aos turistas [...] desfrutam as mesmas atividades que os visitantes turistas [...] residentes visitam partes das cidades que são novas para eles ou que oferecem atrativos particulares, como as áreas centrais".

\footnotetext{
${ }^{3}$ Walter Benjamin descrevendo o flâneur em "Charlers Baudelaire: A Lyric Poet in an Era of High Capitalism".

${ }^{4}$ É importante ter em visa algumas ponderações de ordem semântica, vide o fato de que nos estudos e pesquisas de transportes urbanos, por exemplo, a palavra "viagem" é correntemente usada para nominar os deslocamentos internos a uma aglomeração urbana
} 
Do ponto de vista espacial, quaisquer porções do tecido urbano poderão ensejar o turismo urbano, desde aquelas mais explicitamente reconhecidas como turísticas (pela presença dos seus sujeitos, os turistas, e a oferta de serviços e atrativos) até expressões espaciais mais corriqueiras - ou cotidianas (MAITLAND, 2010) -, que, em princípio, representariam aspectos banais da vida urbana. Por mais que não seja fácil - ou mesmo possível - isolar o "uso específico de espaços na experiência urbana dos visitantes" (HAYLLAR et al, 2008, p. 8), alguns elementos podem aparecer como dominantes no contexto urbano, como infraestrutura, rede de serviços e facilidades turísticas. Este é o caso dos atrativos (ou atrações) turísticos, elemento básico do turismo, que "oferece aos visitantes atividades passivas e também mais ativas que ocupam o tempo de suas visitas" (PAGE, 1995, p. 70).

Depreende-se que o consumo turístico não está vinculado apenas ao consumo de mercadorias e serviços, senão de situações que ensejam experiências urbanas, incluindo o consumo simbólico do lugar. Esta concepção amplia a ideia de cidade como "produto" na acepção de Page (1995), Law (2002) e Ashworth e Voogd (1990), situações nas quais a "leitura de textos culturais, como as paisagens e as representações de destinações turísticas" levam em conta também os que "residentes [que] consomem representações e paisagens das destinações turísticas urbanas" (SELBY, 2004b, p. 86).

No que tange à gestão urbana - e particularmente às intervenções urbanas -, Spirou (2011, p. 155) lembra que no "projeto de uso misto de um waterfront ${ }^{5}$, a implantação de restaurantes étnicos e áreas especiais não estimulam apenas o turismo, mas também servem de ímã para indivíduos que julgam tais facilidades como centrais em suas vidas”. Do ponto de vista da política urbana, ações como essas seduzem o morador para fruir sua própria cidade, de maneira que, se essa movimentação financeira não gera receita externa para a economia urbana, ao menos pode ser um mecanismo para conter sua saída.

Desconsiderar este sujeito-morador nos estudos turísticos pode significar um equívoco, especialmente para as formas de turismo que se observam em grandes aglomerações urbanas

\footnotetext{
5 Não existe uma tradução precisa para "waterfront" na Língua Portuguesa, termo que costuma ser usado sem tradução nos estudos urbanos. Mas pode-se dizer que são todas as "frentes de água" das cidades, voltadas para rios, lagos ou mares, normalmente - ainda que não sempre - coincidindo com as primeiras porções historicamente ocupadas no processo de formação urbano das cidades.
} 
altamente centradas nas experiências de sua própria urbanidade. É importante reter a ideia da coincidência espacial, ou seja, independentemente do local de residência do visitante, existem convergências espaciais para certas partes da cidade, cujas experiências são vividas por vários tipos de visitantes. No caso de grandes aglomerações urbanas, este deslocamento para atividades não rotineiras, que se aproximam do campo do turismo, envolvem distâncias significativas, embora sem pernoite. Disso resulta que, nos momentos de tempo livre, ao escolher os atrativos turísticos da "cidade tradicional" - ou optar por qualquer outra atividade no núcleo de uma região metropolitana, por exemplo - é possível imaginar que seu comportamento, em certos aspectos, venha a se assemelhar - porém, não efetivamente se igualar - ao de turistas.

Como síntese, pode-se assumir que o sujeito do turismo urbano são os "consumidores de lugar", categoria que engloba aqueles que consomem, experienciam ou fruem a cidade, sejam moradores ou turistas. Com isso, fica evidente que o turismo poderá ter um papel diferente no âmbito das dinâmicas socioespaciais das grandes cidades, ainda que represente apenas uma parcela das estratégias de seu desenvolvimento (FAINSTEIN, GLADSTONE, 1999; PAIVA, 2011).

\section{O Turismo em São Paulo: verificaçõe sempíricas e proposições metodológicas}

Wöber (2000) e Vandermey (1984) elencam dificuldades ao analisar a dinâmica do setor de turismo na escala das cidades, dado que autoridades de turismo trabalham com dados nacionais ou regionais. Além disso, quando as estatísticas focam-se em segmentos específicos, o turismo urbano dificilmente é contemplado na sua totalidade, tendo em vista a dificuldade de se isolar variáveis específicas no âmbito de grandes cidades.

No caso de São Paulo, pesquisas nas Centrais de Informação Turística (CITs) indicam, para o período 2006-2011, que o MASP é o local mais visitado por expressiva parcela dos respondentes (16,8\%), seguido de Mercado Municipal Paulistano (10,6\%) e Parque do Ibirapuera (6,7\%). Há, ainda, indicações de regiões da cidade mais procuradas, como Avenida Paulista e Centro Histórico (Tabela 1). 
Tabela 1 - Locais mais visitados segundo pesquisas nas CITs - 2006-2010

\begin{tabular}{lcc}
\multicolumn{1}{c}{ Locais mais visitados } & \multicolumn{2}{c}{ Tipo de visitante } \\
Excursionista
\end{tabular}

Fonte: Allis (2012), com dados do Observatório do Turismo de São Paulo (2011)

As pesquisas junto aos visitantes sem pernoites (ou excursionistas) indicam um cenário semelhante, com o MASP, o Mercado Municipal Paulistano e o Parque do Ibirapuera como os mais visitados. Já a Rua 25 de Março e o bairro da Liberdade também são regiões citadas, mas não pelos visitantes com pernoites sugerindo que, no caso dos excursionistas, existe uma importante demanda por compras - já que aquelas áreas oferecem oportunidades únicas de preço e diversidade de produtos.

Particularmente, em relação ao Mercado Municipal Paulistano, um dos ícones turísticos da cidade - especialmente após sua reforma e expansão em 2000, com recursos do Programa Monumenta - a maior demanda de visitantes origina-se na própria Região Metropolitana ou de cidades do interior de São Paulo. Com efeito, 60\% dos visitantes do Mercado Municipal Paulistano realizam visitas conjugadas, mais focadas nas compras (24\%), do que por motivações histórico-culturais. Nesta categoria, atrativos como Pinacoteca do Estado, Museu da Língua Portuguesa, Edifício Banespa, Catedral da Sé, Mosteiro de São Bento, Igreja de Santo Antonio e Espaço Catavento, surgem como os mais procurados (ALLIS, 2009). Em quaisquer dos casos, é importante notar que os locais citados localizam-se num raio de não mais do que um quilômetro do Mercado, sugerindo que o Centro de São Paulo pode ser considerado uma região turística bem articulada, tendo no Mercado Municipal Paulistano uma atração de alta relevância. 
As demais pesquisas da SPTuris mostram, desde 2008, situações relacionadas ao afluxo de pessoas em eventos. No biênio 2010-2011, observa-se uma leve tendência de diminuição do público local: no São Paulo Fashion Week os moradores da Capital passam de 77,6\% para 75,8\%; na Parada LGBT, de 87,4\% para cerca de 82,1\% e, na Virada Cultural, de 91,7\% para 90,3\%. No entanto, este cenário não se repete para o Formula Indy e o Carnaval, cuja afluência de moradores aumenta significativamente em 2011 (Tabela 2).

Tabela 2 - Estatísticas gerais sobre eventos paulistanos - 2010-2011

\begin{tabular}{|c|c|c|c|c|c|c|c|}
\hline \multirow{2}{*}{ EVENTOS } & \multirow{2}{*}{$\begin{array}{l}\text { Público } \\
\text { Estimado }\end{array}$} & \multicolumn{5}{|c|}{ Motivações de visita (\%) } & \multirow{2}{*}{$\begin{array}{c}\text { Procedência } \\
\text { São Paulo } \\
\text { (\% do total) }\end{array}$} \\
\hline & & Evento & Lazer & Negócios & VAP & Estudo & \\
\hline Carnaval (2010) & 110.000 & $70,9 \%$ & $5,4 \%$ & $12,9 \%$ & $10,8 \%$ & $0,0 \%$ & $70,6 \%$ \\
\hline Carnaval (2011) & $\mathrm{n} / \mathrm{i}$ & $79,6 \%$ & $5,9 \%$ & $10,5 \%$ & $4,0 \%$ & $0,0 \%$ & $77,4 \%$ \\
\hline Formula Indy 300 (2010) & 60.000 & $\mathrm{n} / \mathrm{i}$ & $\mathrm{n} / \mathrm{i}$ & $\mathrm{n} / \mathrm{i}$ & $\mathrm{n} / \mathrm{i}$ & $\mathrm{n} / \mathrm{i}$ & $56,3 \%$ \\
\hline Formula Indy 300 (2011) & 45.000 & $84,9 \%$ & $5,4 \%$ & $4,8 \%$ & $4,8 \%$ & $0,0 \%$ & $63,4 \%$ \\
\hline Virada Cultural (2011) & $\mathrm{n} / \mathrm{i}$ & $64,3 \%$ & $13,9 \%$ & $7,0 \%$ & $13,9 \%$ & $0,9 \%$ & $91,7 \%$ \\
\hline Virada Cultural (2011) & 4.000 .000 & $65,4 \%$ & $13,4 \%$ & $11,8 \%$ & $9,4 \%$ & $0,0 \%$ & $90,3 \%$ \\
\hline Parada LGBT (2010) & $\mathrm{n} / \mathrm{i}$ & $72,1 \%$ & $17,2 \%$ & $4,1 \%$ & $0,8 \%$ & $5,7 \%$ & $87,4 \%$ \\
\hline Parada LGBT (2011) & 4.000 .000 & $80,6 \%$ & $\mathrm{n} / \mathrm{i}$ & $\mathrm{n}$ & $\mathrm{n} / \mathrm{i}$ & $\mathrm{n} / \mathrm{i}$ & $82,1 \%$ \\
\hline SP FashionWeek (2010) & 100.000 & $55,0 \%$ & $9,5 \%$ & $28,4 \%$ & $7,1 \%$ & $0,0 \%$ & $77,6 \%$ \\
\hline SP FashionWeek (2011) & 70.000 & $74,0 \%$ & $5,1 \%$ & $17,1 \%$ & $3,4 \%$ & $\mathrm{n} / \mathrm{i}$ & $75,8 \%$ \\
\hline Formula Truck (2010) & 50.000 & $\mathrm{n} / \mathrm{i}$ & $\mathrm{n} / \mathrm{i}$ & $\mathrm{n} / \mathrm{i}$ & $\mathrm{n} / \mathrm{i}$ & $\mathrm{n} / \mathrm{i}$ & $65,6 \%$ \\
\hline Bienal do Livro (2010) & 740.000 & $84,3 \%$ & $8,8 \%$ & $3,0 \%$ & $2,2 \%$ & $1,7 \%$ & $60,6 \%$ \\
\hline Salão do Automóvel (2010) & 750.000 & $92,3 \%$ & $2,6 \%$ & $2,6 \%$ & $2,0 \%$ & $0,5 \%$ & $41,3 \%$ \\
\hline $\begin{array}{l}\text { GP Brasil Formula } 1 \\
(2010)\end{array}$ & 110.000 & $\mathrm{n} / \mathrm{i}$ & $\mathrm{n} / \mathrm{i}$ & $\mathrm{n}$ & $\mathrm{n} / \mathrm{i}$ & $\mathrm{n} / \mathrm{i}$ & $60,0 \%$ \\
\hline
\end{tabular}

Fonte: Allis (2012), com dados do Observatório do Turismo de São Paulo (2011)

\subsection{Considerações metodológicas}

Para a condução da pesquisa empírica, tomou-se como unidade de observação os atrativos turísticos da cidade de São Paulo, cuja visitação pode ser feita tanto pelo turista (principalmente o que escolhe a cidade por motivações de lazer principais ou secundárias), quanto pelo morador, que desfruta da oferta destes equipamentos em seu tempo de lazer. Nesta seleção, foram desconsideradas atividades não abrigadas por edificações e que não 
tivessem controle de acesso $^{6}$ (ruas de comércio especializado ou de concentração de interesses como as praças áreas urbanas ou bairros específicos), não por serem de menor importância, senão porque, considerados os objetivos desta pesquisa, sua análise exigiria a aplicação de outro percurso teórico-metodológico.

Inicialmente a seleção dos atrativos turísticos foi feita a partir da consulta a seis guias turísticos da cidade de São Paulo online, com base em sua relevância comercial (Guia Quatro Rodas, Frommer's, Fodor's e Lonely Planet) ou oficialidade das fontes, nos casos em que o formato fosse apenas digital (site da SPTuris, como entidade oficial de turismo da cidade, e do Ministério do Turismo). As consultas às bases digitais foram feitas no primeiro semestre de 2011. A escolha dos atrativos, objeto de pesquisa e análise, baseou-se na sua ocorrência em pelo menos dois destes guias, de maneira a excluir aqueles atrativos que possam ter sido indicados de maneira casual, não representando, isoladamente, o foco da atratividade turística da cidade. A Figura 1 mostra, além da localização dos 52 atrativos resultantes da seleção, os perímetros de outros projetos urbanos em São Paulo (como as Operações Urbanas ${ }^{7}$, o Programa Monumenta - já finalizado, o Nova Luz atualmente suspenso, e Projeto de Desenvolvimento Turístico do Centro, realizado pela SPTuris) e, ainda, o grau de exposição destes atrativos selecionados, em que pese sua recorrências nos diferentes guias turísticos consultados (desde uma única vez - o que não o qualifica para a lista de referência - até mais de cinco).

\footnotetext{
${ }^{6}$ Vale registrar que "volume de visitantes" talvez não se seja o melhor indicador sobre a realidade turística de um destino, especialmente porque as experiências turísticas - em particular, nas grandes cidades - não está confinada às fronteiras físicas dos atrativos turísticos. No entanto, esses dados possibilitaram algumas inferências sobre a dinâmica do turismo na cidade. Em suma, do ponto de vista estatístico, as informações sobre o volume de visitantes poderia cobrir lacunas sobre as características gerais dos turistas da cidade, conquanto, até o presente, não se realizou uma ampla pesquisa de caracterização e dimensionamento dos fluxos turísticos da cidade.

${ }^{7}$ As Operações Urbanas Consorciadas (OUC) são mecanismos de gestão urbana previstos no chamado Estatuto das Cidades (Lei 10.257/2001), mas que, com algumas diferenças operacionais, já vinham sendo aplicados em S. Paulo desde a década de 1980. Em suma, trata-se de um "conjunto de intervenções e medidas coordenadas pelo Poder Público municipal, com a participação dos proprietários, moradores, usuários permanentes e investidores privados, com o objetivo de alcançar em uma área transformações urbanísticas estruturais, melhorias sociais e a valorização ambiental". Dentre outras medidas, podem ser previstas: "I a modificação de índices e características de parcelamento, uso e ocupação do solo e subsolo, bem como alterações das normas edilícias, considerado o impacto ambiental delas decorrente; II a regularização de construções, reformas ou ampliações executadas em desacordo com a legislação vigente; III a concessão de incentivos a operações urbanas que utilizam tecnologias visando a redução de impactos ambientais, e que comprovem a utilização, nas construções e uso de edificações urbanas, de tecnologias que reduzam os impactos ambientais e economizem recursos naturais, especificadas as modalidades de design e de obras a serem contempladas" (BRASIL, 2001).
} 
A partir desta seleção, buscou-se entender a dinâmica de visitação entre moradores e turistas, a partir de consultas aos gestores destes atrativos turísticos selecionados. A intenção era consolidar algumas informações de natureza quantitativa, já que, observada a literatura sobre o tema (LAW, 2002), notou-se que a geração e o tratamento de informações são sérios limitantes para o estudo, o planejamento e a gestão do turismo urbano, o que também se confirmou em São Paulo.

As consultas aos gestores dos atrativos foram realizadas a partir de julho de 2011, por meio de formulário eletrônico estruturado, dividido em três blocos: caracterização geral dos atrativos, dinâmica de visitação (para o período 2006 e 2010, distribuídas conforme a origem dos visitantes: local, metropolitano, estadual, nacional e internacional) e impressões dos gestores sobre a imagem turística de São Paulo - sendo que as respostas para este último item foram muito genéricas e, por ora, descartadas da análise. 


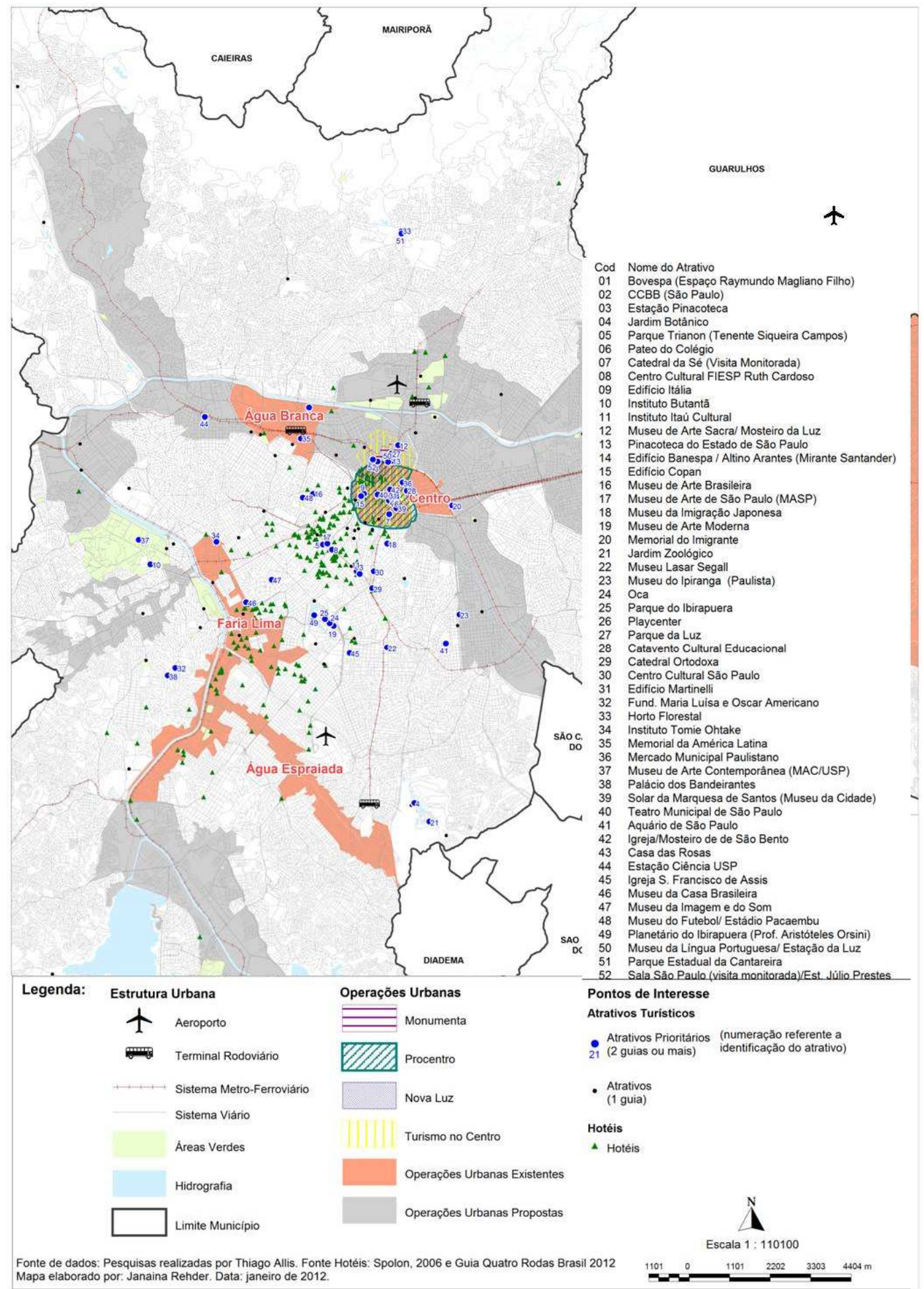

Figura 1 - Localização de Atrativos Turísticos selecionados de São Paulo

Fonte: Allis (2012) (coleta de dados em 2011) 


\section{Discussão de resultados}

Com relação às coletas realizadas junto aos atrativos turísticos (ou seja, pelo lado do gestor da oferta turística), os resultados foram modestos, tendo em vista a quase total negligência com o controle de fluxos nos atrativos pesquisados e a reduzida abrangência das coletas. Frisa-se que, mesmo quando os gestores informam realizar a estratificação de origens dos visitantes, não necessariamente conduzem um efetivo controle (ou seja, onde existem mecanismos para se identificar a origem dos visitantes, são poucos os dados sistematizados e disponíveis por conta de coletas truncadas ou intermitentes).

Dos 52 atrativos listados, obtiveram-se informações de 35, porém nem todos os formulários foram preenchidos a contento - seja pela ausência das informações por parte dos gestores dos atrativos (o que, normalmente, vinha explicado no campo final do formulário), seja por outras razões não justificadas. No conjunto, estes atrativos foram responsáveis por mais de 16 milhões de visitas entre 2006 a 2010 - o que não deve ser confundido como visitantes, já que um mesmo visitante pode fazer várias visitas a atrativos distintos, durante sua estada na cidade $^{8}$.

As formas de controle de visitantes mais comuns é a contagem de bilhetes (feito em $42,9 \%$ dos atrativos), o uso de livro de visitantes $(22,9 \%)$ e controle visual $(22,9 \%)$. Chama atenção a baixa incidência de uma pesquisa contínua, o que poderia indicar uma prática rotineira de acompanhamento do perfil dos visitantes, por exemplo. Pelas respostas, apenas o Teatro Municipal conduz coletas sistemáticas.

O controle de visitação, com contagem estratificada pelo local de residência do visitante, é feito, efetivamente, somente no Museu da Língua Portuguesa, no Espaço Raymundo

8 Estes números, na realidade, referem-se a 20 atrativos para os quais foram fornecidas informações sobre visitação (resposta completa). Não se obtiveram dados sobre volumes de visitantes de 12 atrativos (resposta parcial): Playcenter, Estação Ciência, Solar da Marquesa de Santos, Pavilhão Japonês, Pinacoteca do Estado de São Paulo, Edifício Itália, Pateo do Collegio, Mercado Municipal Paulistano, Mosteiro de São Bento, Copan e Centro Cultural FIESP. Nesta contagem, não foram considerados as visitas realizadas aos parques, cujo acesso é livre e, portanto, geraria uma distorção nos dados. A título de registro, o Parque da Luz estima-se, em 2010, foi visitado por pelo menos 1,3 milhão de pessoas tenham; no Parque do Ibirapuera, segundo pesquisas feitas, em 2007, estima-se que o volume mensal de usuários teria chegado a 1,15 milhão (portanto, mais de 13 milhões anuais); no Parque Tenente Siqueira Campos (TRIANON), informações dos gestores indicam que as visitas anuais sejam da ordem de quatro mil. 
Magliano Filho (BOVESPA) e no Prédio Martinelli, cujos dados de visitação foram dispostos em função da origem dos visitantes. Na resposta aos formulários, gestores de outros três atrativos informaram que dispõem de mecanismos de monitoramento da origem dos visitantes, entretanto não informaram os dados estratificados.

Os dados de $2010^{9}$ para os atrativos onde se faz a estratificação das origens dos visitantes apontam os moradores da cidade de São Paulo como maior grupo a contribuir para o total de visitantes: 52\% no Museu da Língua Portuguesa, 70,3\% no Espaço Raymundo Magliano (Bovespa) e 66,4\% no Prédio Martinelli. A presença de estrangeiros é ínfima e, no geral, a visitação realizada por turistas de outros Estados não é desprezível - principalmente no Museu da Língua Portuguesa e no Prédio Martinelli (Figura 2).

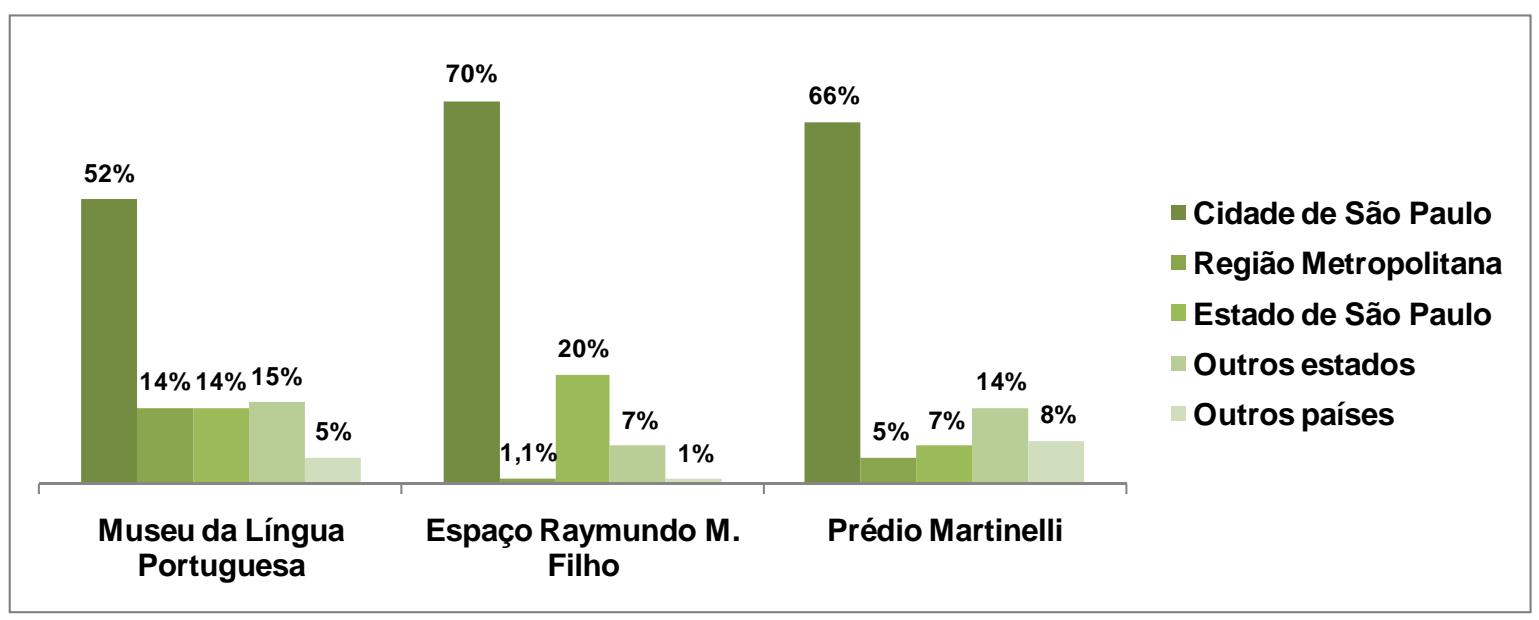

Figura 2 - Origens dos visitantes a atrativos turísticos de S. Paulo - 2010 Fonte: Allis (2012) (coleta de dados em 2011)

Esta situação ajuda a desconstruir a ideia de que o turismo urbano, feito em grandes cidades, explica-se preponderantemente por fluxos turísticos internacionais (ainda que seja recorrente a presença de fluxos estrangeiros nas principais metrópoles do mundo). No Museu do Louvre, um dos maiores ícones turísticos do mundo, $22 \%$ dos visitantes eram provenientes de Paris ou

\footnotetext{
${ }^{9}$ Neste ano, o Museu da Língua Portuguesa recebeu 385.025 visitantes, o Espaço Raymundo Magliano Filho (BOVESPA), 105.039 e o Prédio Martinelli, 4.013. Fixou-se este ano, pois, no recorte histórico proposto (20062010), apenas em 2010 haviam dados disponíveis para os três.
} 
da Île-de-France entre os anos de 1995-1996; entre 1981 e 1996, 17\% dos visitantes do Museu Britânico, em Londres, residiam na Grande Londres; considerados a média de todos os museus da cidade, o volume de residentes a compor o total de visitantes chega a 29\% (LAW, 2002 , p. 80, 86). Por isso, em qualquer cidade onde o turismo urbano é uma estratégia, os públicos locais tendem a representar importantes demandas para os atrativos turísticos. E do ponto de vista de políticas de lazer, isto deveria ser um compromisso da mais alta relevância por parte dos gestores locais - já que seus impactos vão além dos benefícios aos turistas.

Os dados de visitação do Mercado Municipal Paulistano, do Museu da Língua Portuguesa, do Espaço Raymundo Magliano Filho (BOVESPA) e do Prédio Martinelli, no Centro da Cidade - onde coincidem muitas iniciativas de projetos urbanos nos últimos 20 anos - confirmam a Região Metropolitana de São Paulo como principal origem dos visitantes registrados.

Os críticos às intervenções urbanas (por exemplo, projetos de recuperação de áreas centrais), principalmente em cidades como São Paulo, que usam como argumento contrário o fato de os aportes financeiros serem direcionados para captar interesse e atender a demandas de turistas, parecem estar equivocados (ou não compreender todas as facetas da questão), pois as transformações decorrentes destes projetos podem ter grande utilidade para o morador da cidade e região, imprimindo maior mérito à gestão urbana local. Logicamente, se estas intervenções beneficiam moradores, também deverão ser de valia para quem visita a cidade, propiciando um espaço urbano acolhedor e hospitaleiro, ensejando a uma maior permanência e reforçando a intenção do retorno (FERRAZ, 2013). Vide o exemplo de Curitiba, destino turístico altamente demandado, em que os principais atrativos e imagens turísticos são, em essência, equipamentos de lazer disponibilizados para a população - principalmente parques urbanos.

\section{Algumas Conclusões Possíveis}

Saber as quantidades de visitantes de uma cidade não é a única ou mesmo a principal forma de analisar o turismo urbano, já que se trata de um fenômeno de grande complexidade espacial e, portanto, permeado de sutilezas que extrapolam as abordagens quantitativas. No entanto, decidiu-se pela tentativa de quantificação de fluxos com as informações fornecidas 
por gestores dos atrativos turísticos de São Paulo como caminho para fazer algumas inferências gerais sobre a dinâmica turística paulistana.

O fato de que parte significativa dos visitantes da cidade é formada por moradores de São Paulo e municípios vizinhos reforça a discussão sobre os significados e práticas de turismo em grandes cidades como São Paulo, abrindo espaço para maiores reflexões sobre definições e conceitos convencionais - particularmente as definições e convenções da OMT. O movimento pendular - de outras regiões da cidade ou de municípios próximos -, que qualifica um claro cenário de excursionismo, é um dos elementos definidores do turismo paulistano, situação especialmente importante quando se leva em conta que são atrativos turísticos de grande importância na oferta turística paulistana (principalmente o Museu da Língua Portuguesa). Some-se a esta análise as grandes vias de conexão fácil e segura entre São Paulo e grandes e médias cidades do interior paulista: esta condição facilita e estimula a vinda de visitantes em busca de atividades de lazer (visitas a museus e teatros, fruição da vida noturna e a gastronomia etc), sem contar o afluxo de pessoas para compras, tratamentos de saúde, cursos e formação.

Ainda que os resultados empíricos tenham sido modestos, o retorno às consultas pode ser considerado satisfatório (35 no total) para o panorama de estudo (52 atrativos selecionados). Entretanto, a questão fulcral não foi perfeitamente respondida pela maior parte dos gestores dos atrativos - qual seja, a estratificação dos visitantes por origem (residência). A baixa incidência de controle dos visitantes nos atrativos levantados, por si só, já pode ser considerado um resultado elucidativo: em geral, não existem sistemáticas para se conhecer o público dos atrativos turísticos paulistanos. $\mathrm{E}$ isso sugere um cenário mais sério do que se imagina, afinal, a contagem não se justifica por mera formalidade ou burocracia, mas como uma ferramenta estratégica e elementar na gestão do turismo urbano. A ausência destes dados priva de subsídios essenciais as políticas públicas intentadas nas grandes cidades - e isso não seria diferente para São Paulo.

Ademais, se em situações onde é perfeitamente possível contar os visitantes e abordá-los para pesquisas, esta tarefa não é cumprida a contento, imagine-se quão distante se está de uma compreensão mais sutil do turismo em outros ambientes (ruas de comércio especializado, zonas de entretenimento e gastronomia, etc.), onde as experiências turísticas se dão de 
maneira difusa no território - embora já existam iniciativas de pesquisas com relação ao turismo de compras (IANNICELI, VARGAS, 1999). Experiências com tecnologia da informação, mediante ferramentas de geolocalização e os chamado "big data", produzidos em profusão e de maneira espontânea por usuários de aparelhos celulares com internet móvel, já começam a compor metodologias de pesquisa em turismo urbano, como nas pesquisas relatadas por Edwards et al (2010), Shoval (2008), Shoval e Isacsson (2007), Lew e McKercher (2006), dentre outros ${ }^{10}$.

Como argumentado anteriormente, não havia a hipótese de assumir que morador seja turista ainda que os comportamentos espaciais, por vezes, possam sugerir que sim. Contudo, no arcabouço do turismo urbano - que exige uma leitura detalhada das interfaces do turismo com espaços urbanos - parece possível tratar turistas e moradores como sujeitos da mesma atividade, convivendo em suas experiências urbanas e compartilhando espaços e serviços urbanos, valorizando análises que levem em conta o "comportamento espacial" (EDWARDS et al, 2010) de visitantes da e na cidade. Para esta tarefa, buscamos tratar e assimilar extensivamente amplo referencial teórico sobre turismo urbano, desde os precursores (HALL, 1987; PAGE, 1995; LAW, 2002; PEARCE, 1999, 2001; VARGAS, 1996, 1998a, 1998b) até os mais atuais (MAITLAND, 2010; SPIROU, 2011).

Do ponto de vista teórico, em linha com as discussões de Maitland (2010), talvez se construa, mediante maiores discussões sobre o tema, o conceito de turismo intra-urbano, como forma de incorporar, nos estudos urbanos e do turismo, a ideia de que os moradores, em certas situações, seriam assimilados como turistas. Contudo, seriam convenientes mais lastros conceituais - como aquelas propostas por Martinotti (1994), a estudar a morfologia das cidades em função dos vários "usuários" - e observações empíricas em maior recorrência, para se avançar nessas considerações. Mesmo porque, turismo interno também se confundiria com a terminologia utilizada para definir o turismo realizado internamente a um país, ou seja, o turismo doméstico.

\footnotetext{
${ }^{10}$ Em caminho semelhante, Allis coordena, com apoio do $\mathrm{CNPq}$, o projeto de pesquisa $A$ dinâmica territorial dos fluxos turísticos em espaços urbanos, que se configura como "o piloto de um modelo para identificação e análise de fluxos turísticos na escala urbana, a partir do rastreamento dos deslocamentos realizados pelos visitantes em destinos turísticos".
} 
Vale ressaltar, no entanto, que diferente de outras grandes cidades do mundo, São Paulo não tem um banco de dados detalhado sobre a dinâmica de visitação de seus atrativos - inclusive, sem ter feito, até o momento, uma pesquisa de demanda completa, ampla e detalhada. Sem desconsiderar esforços das autoridades locais, mormente do Observatório de Turismo de São Paulo, são imprescindíveis mais e melhores pesquisas sobre turismo urbano em grandes cidades - com especial atenção a metodologias inovadoras - que reconheçam suas particularidades, especialmente quandoo Brasil tem mais de 10 cidades com mais de um milhão de habitantes.

Se esta pesquisa fez um recorte nos atrativos turísticos, múltiplas podem ser as futuras abordagens, tais como tratar de setores específicos que compõem o turismo na cidade, como gastronomia, vida noturna e teatros. Buscar leituras fenomenológicas sobre o turismo urbano, dando atenção para "tribos" ou certas áreas urbanas, entender a distribuição espacial dos fluxos turísticos em função das centralidades turísticas, etc. são outras ações que se fazem necessárias - e o arcabouço teórico-metodológico da antropologia urbana, por exemplo, pode estruturar uma abordagem altamente profícua.

Portanto, a relação entre os fluxos turísticos, a disposição (ou distribuição) dos atrativos turísticos (entendendo estes como elementos geradores de interesse, por qualquer razão e em qualquer escala) e as políticas de planejamento e gestão urbanos ilumina um conjunto de questões altamente importantes para o estudo do turismo em grandes cidades. Ou seja, a articulação entre oferta e demanda turística, em grandes cidades, oportuniza a construção de um campo conceitual que, até hoje, assenta-se no que se reconhece como "turismo urbano". Há que atentar para as formas e as dinâmicas urbanas ensejadas em grandes aglomerações urbanas e para as possibilidades de mobilidades turísticas aí observadas, o que exige tratamento cuidadoso e muito particularizado, sendo interessante continuar uma relativização das referências convencionais de turismo e mesmo de cidade (ALLIS, 2014).

\section{Referências}

ALLIS, T. Viajantes, visitantes, turistas... Em busca de conceitos em um mundo urbano. Caderno Virtual de Turismo. Edição especial: Hospitalidade e políticas públicas em turismo. Rio de Janeiro,v. 14, supl.1, s.23-38, 2014. 
ALLIS, T. Grandes projetos urbanos e turismo: o caso de São Paulo. 2012. Tese de doutorado (Arquitetura e Urbanismo), Faculdade de Arquitetura e Urbanismo, Universidade de São Paulo, São Paulo, 2012.

ALLIS, T. "Tourist mobility and public urban space in developing countries: the case of São Paulo". In: $2^{\text {nd }}$ UNESCO-ICCROM Asian Conference for Heritage Management (2009) - Macao (China). Anais...

ASHWORTH, G. J.; VOOGD, H. Selling the city: marketing approaches in public sector urban planning. Londres: Belhaven, 1990.

BRAGA, D. C. À margem das feiras de negócios: o uso do tempo livre do turista em São Paulo. 2005. Tese de doutorado - (Ciências da Comunicação), Escola de Comunicações e Artes, Universidade de São Paulo, São Paulo, 2005.

BRASIL, Lei 10.257, de 10 de Julho de 2001. Regulamenta os arts. 182 e 183 da Constituição Federal, estabelece diretrizes gerais da política urbana e dá outras providências. Palácio do Planalto. 2001. Disponível em: <http://www.planalto.gov.br/ccivil_03/leis/LEIS_2001/L10257.htm>. Acesso em: 20 Ago. 2015.

BULL, P., CHURCH, A. "Understanding urban tourism: London in the early 1990s". International Journal of Tourism Research, v. 3, p. 141-150, 2001.

CARVALHO, M. A. Cidade global, destino mundial: turismo urbano em São Paulo. 2011. Tese de doutorado - (Geografia Humana), Faculdade de Filosofia, Letras e Ciências Humanas, Universidade de São Paulo, São Paulo, 2011.

COLES, T. "Urban tourism, place promotion and economic restructuring: the case of post-socialist Leipzig". Tourism Geographies, v. 5, n. 2, 2003, p. 190-219.

COSTA, C. "An emerging tourism planning paradigm? A comparative analysis between town and tourism planning". International Journal of Tourism Research, v. 3, 2001, p. 425-441.

EDWARDS, D.; GRIFFIN, T.; HAYLLAR, B. "Urban tourism research: developing an agenda". Annals of Tourism Research, v. 35, n. 4, 2008, p. 1032-1052.

EDWARDS, D.; DICKSON, T.; GRIFFIN, T.; HAYLLAR, B. Tracking the urban visitor: methods for examining tourists' spatial behavior and visual representations. IN: RICHARDS, G.; MUNSTERS, W. Cultural tourism research methods. CAB International, 2010, p. 104-114.

FERRAZ, V. S. Hospitalidade Urbana em grandes cidades: São Paulo em foco. 2013. Tese de doutorado - (Arquitetura e Urbanismo), Faculdade de Arquitetura e Urbanismo, São Paulo. 2013

GARCIA, M.; CLAVER, N. Barcelona: governing coalitions, visitors, and the changing city centre. In: FAINSTEIN, S., JUDD, D. (Eds.). Cities and visitors: regulating people, markets and city space. Oxford: Blackwel, 2003, p. 113-125.

HALL, P. "Urban developmentand the future of tourism". Tourism Management, 1987, p. 129-130.

HANNAGAN, J. Fantasy city: pleasure and profit in the postmodern metropolis. Abingdon, Rouledge, 2006 (1998).

HAUSSERMANN, H., COLOMB, C. The new Berlin: marketing the city of dreams. In: HOFFMANN, L.; FAINSTEIN, S., JUDD, D. (Eds.). Cities and visitors: regulating people, markets and city space. Oxford: Blackwel, 2003, p. 200-218.

HAYLLAR, B.; GRIFFIN, T.; EDWARDS, D. Urban tourism precincts: engaging with the field. In: HAYLLAR, B.; GRIFFIN, T.; EDWARDS, D. (Orgs.). City spaces, tourist places: urban tourism precincts. Oxford: Elsevier, 2008, p. 3-18. 
IANACELLI, E. Z.; VARGAS, H. C. Turismo de Compras: 25 de março. Relatório de pesquisa de iniciação científica. São Paulo: FAUUSP. jan 1999 (mimeo).

JUDD, D. R.; FAINSTEIN, S.S. (Orgs.).The tourist city. New Haven: Yale University Press, 1999, p. $35-53$.

LAW, C. M. Urban tourism: the visitor economy and the growth of large cities. 2.ed. Londres: Continuum, 2002.

LEW, A.; MCKERCHER, B. Modeling tourist movements: a local destination analysis. Annals of Tourism Research, v. 33, n. 2, p. 403-423, 2006.

LUCCHIARI, M. T. D. P. Urbanização turística: um novo nexo entre o lugar e o mundo. In: SERRANO, C.; BRUHNS, H. T.; LUCCHIARI, M. T. D. P. (Orgs). Olhares contemporâneos sobre o turismo. 3. ed. Campinas: Papirus, 2004 (2000), p. 105-130

MAITLAND, R. "Everyday life as a creative experience in cities". International Journal of Culture, Tourism and Hospitality Research, v. 4, n. 3, 2010, p. 176-185.

MARTINOTTI, G. The new social morphology of cities. Disponível em: <http://www.unesco.org/most/wien/guido.htm>. Acesso em: 20 de setembro de 2013.

MULLINS, P. “Tourism urbanization”. International Journal of Tourism Research, v. 14, n. 3, 1991, p. 326-342.

OBSERVATÓRIO DO TURISMO DE SÃO PAULO. Disponível em: <www.observsatoriodoturismo.com.br〉. Acesso em: 20 nov. 2011.

PAGE, S. Urban tourism. Londres: Routledge, 1995.

PAIVA, R. A. A metrópole híbrida: o papel do turismo no processo de urbanização da região metropolitana de Fortaleza. 2011. Tese de doutorado - (Arquitetura e Urbanismo), Faculdade de Arquitetura e Urbansimo, Universidade de São Paulo, São Paulo, 2011.

PEARCE, D. G. "Tourism in Paris: studies at the microscale". Annals of Tourism Research, v. 26, n. 1, p. 77-97, 1999.

PEARCE, D. G. "An integrative framework for urban tourism research". Annals of Tourism Research, v. 28, n. 4, p. 926-946, 2001.

PEARCE, D. G. Geografia do turismo: fluxos e regiões no mercado de viagens. São Paulo: Aleph, 2003. (Série Turismo).

ROGERSON, C. M. "Urban tourism in the developing world: the case of Johannesburg". Development Southern Africa, v. 19, n. 1, p. 169-189, 2002.

SÁNCHEZ, F. A reinvenção das cidades para um mercado mundial. 2. ed. Chapecó: Argos, 2010.

SÃO PAULO TURISMO S/A. Plano Municipal de Turismo: 2011-2014. Disponível em: <www.cidadedesaopaulo.com/comtur〉. Acesso em: 20 nov. 2011.

SÃO PAUlO TURISMO S/A. Projeto de Desenvolvimento Turístico do Centro de São Paulo. Disponível em: <www.spturis.com/turismocentro>. Acesso em: 20 ago 2011.

SASSEN, S. The global city: New York, London and Tokyo. Princeton: Princeton University Press, 1991.

SELBY, M. "Consuming the city: conceptualizing and researching urban tourist knowledge". Tourism Geographies, v. 6, n. 2, p. 186-207, 2004a. 
SELBY, M. Understanding urban tourism: image, culture \& experience. Londres, Nova Iorque: I. B. Tauris\&CoLtda, 2004b.

SHIBAKI, V. V. Ícones urbanos na metrópole de São Paulo. Tese de Doutorado - (Geografia Humana), Faculdade Filosofia, Ciências e Letras, Universidade de São Paulo, São Paulo, 2010.

SHOVAL, N. "Tracking Technologies and urban analysis". Cities, v. 25, p. 21-28, 2008.

SHOVAL, N.; ISAACSON, M. "Tracking tourists in the digital age". Annals of Tourism Research, v. 34, p. 141-159, 2007.

SILVA, C. H. C. A reprodução do espaço urbano de São Paulo na perspectiva da hotelaria de alto padrão. 2008. Tese de doutorado - (Geografia), Universidade Estadual Paulista, Rio Claro, 2008.

SPIROU, C. Urban tourism and urban change: cities in a global economy. Nova Iorque, Abindgon: Routeledge, 2011.

SPOLON, A. P. G. Chão de estrelas: hotelaria e produção do espaço urbano em São Paulo, 19952005. 2006. Dissertação de Mestrado - (História e Fundamentos da Arquitetura e do Urbanismo), Faculdade de Arquitetura e Urbanismo, Universidade de São Paulo, 2006.

TELES, R. M. S. Turismo urbano na cidade de São Paulo: o deslocamento do CBD e seus reflexos na hotelaria paulistana. 2006. Tese de doutorado (Relações Públicas, Propaganda e Turismo) - Escola de Comunicações e Artes, Universidade de São Paulo, São Paulo, 2006.

TOLEDO, B.L. São Paulo: Três cidades em um século. São Paulo: DuasCidades, 1983.

VANDERMEY, A. "Assessing the importance of urban tourism: conceptual and measurement issues". Tourism Management, 1984, p. 123-135.

VARGAS, H.C. "Turismo urbano: uma nova indústria motriz". Boletim de Turismo e Administração Hoteleira, Faculdade Ibero Americana, São Paulo, v. 5, n. 2, p. 38-46, 1996. 19, 1998a.

"Turismo e valorização do lugar". Turismo em Análise, ECA-USP, São Paulo, v.9, n.1, p. 7p. G2.

. "Turismo nas grandes cidades Brasileiras. O que falta?" Estado de São Paulo, 21 jul. 1998b,

WÖBER, K.W. "Standardizing European city tourism statistics", Annals of Tourism Research, vol. 27, no. 1, pp. 51-68, 2000.

\section{Recebido em: 18/11/2014 (1 ${ }^{\text {a }}$ versão) 01/09/2015 ( $2^{\text {a }}$ versão) \\ Aprovado em: 29/09/2015}

